\title{
Social Networking Sites and Social Maladjustment - a study among Users and Non Users
}

\author{
Sukanya Rajan ${ }^{1}$, Julian A. Joseph Arthur ${ }^{2}$ \\ ${ }^{1}$ M.Phil Scholar, Department of Psychiatric Social Work, National Institute of Mental Health and Neurosciences \\ (NIMHANS - INI), Bangalore. \\ ${ }^{2} \mathrm{Ph}$. D Scholar, Department of Psychiatric Social Work, National Institute of Mental Health and Neurosciences \\ (NIMHANS - INI), Bangalore. \\ E-mail - arthurjoseph7@gmail.com
}

\begin{abstract}
Background : The past decade has seen a massive upsurge in internet use among people especially on Social Networking Sites (SNS). A new trend among the younger generation is on the rise especially with the advent of smart phones. This current research paper aims to assess the impact of Social Networking Sites on the social maladjustment behavior of students.

Methodology : A descriptive research design was adopted for the study using a census enquiry method for students of the Department of Social Sciences, Lady Doak College, Tamil Nadu, India. A self prepared semi structured questionnaire and Mathews Maladjustment Inventory were used tools used for the study.

Results : Results indicated that Facebook was the most preferred social networking site among the respondents and that they had a high level of social maladjustment $(p=0.039)$. High levels of paranoia and inferiority were also reported.

Conclusions : With the advances in technology and with almost every one being able to access these services on their smart phones the use of SNS will pose a major threat in society for future generations to come. Further research is required to focus on promotion of healthy use of social networking sites so as to promote a better and healthier life style.
\end{abstract}

Keywords: adjustment, social networking, social maladjustment.

\section{INTRODUCTION}

Globally, social networks and blogs are the most popular online category when ranked by average time spent, followed by online games and instant messaging [1]. Social networking sites, electronic mail, instant messaging, video and photo sharing sites are all mediums that help people to communicate and socialize with one another in the virtual world [2]. Several social networking sites exists, "Six.Degrees.com" was the first that came into existence in 1997 allowing users to create profiles, add their friends, surf their friends list and communicate with them [3]. Since then, there has been a tremendous growth in the number of SNS and its users amounting to about 1.5 billion which is an ever increasing number [4]. In 2014, the Pew Research Center found out that the most popular social media site was Facebook. Other platforms like Twitter, Instagram, Pinterest and LinkedIn saw significant increases over the past year in the proportion of online adults who now use their sites [5].

Social Media user's penetration in India is around $8.5 \%$ of the entire population. Internet Users in India is mainly seen in an urban setup where there are $84 \%$ of SNS users which translates to around 110 million social network users in India. This includes users mainly accessing Social networking sites like Facebook, Twitter, LinkedIn and YouTube [6]. Use of social networking sites can be 
addictive to the user and parents can often mistake children for being under the influence of drugs when they performance in studies decreases and behave differently. Most of the times people are so addicted with virtual activities that they were willing to forego their meals, sleep, responsibilities and leisure activities [7]. Use of SNS reduces face to face interaction, reduces attention span, wastage of time and it increases cyber bullying as well as associated with poor academic performance and low motivation. People that frequently use online social networking are also prone to social isolation which can lead to depression and decreased social skills [8].

Teens over share information to the public that can hurt them in the future when trying to get a job, and deleting the information is not good enough. Cyber bullying occurs as well, which is bullying people online in a public way, but occurs at a small percentage. People that frequently use online social networking are also prone to social isolation which can lead to depression and decreased social skills. There is negative effect of SNS usage also; online interaction is replaces the face to face interaction which has an effect on the quality of relationship. Sharing of information to the public can affect the teens in the future and cyber bullying is also common [8]. Also students use social networking to discuss homework topics with peers online, and to get help on assignments [9]. Though studies divulge on both the positive and negative aspects of using social networking sites in the western context, this paper highlights the impact of SNS on social maladjustment among college students.

\section{METHODOLOGY}

The aim of this study was to assess the impact of SNS on social maladjustment among students from the Department of Social Sciences at Lady Doak College, Madurai, Tamil Nadu. A descriptive research design was adopted to describe the social maladjustment behavior among the users and non users of social networking sites. The study adopted a census inquiry where all the students from the Social Sciences Department were recruited for the study. The data was collected during the month of January to May 2013. The tools adopted for data collection was a semi structured questionnaire prepared by the researcher and Mathews Maladjustment Inventory (1975). The Mathews Maladjustment Inventory (MMI) assesses subjects on 5 major aspects of maladjustment i.e. anxiety, depression, mania, inferiority and paranoia. The short form of the same inventory was used to assess the subject's general maladjustment. The test is reported to have high degree of content validity and the coefficient of reliability for the sub scale ranges from 0.6 to 0.9 [10]. The results were analyzed using $\mathrm{R}$ software.

\section{RESULTS}

A total of 170 respondents were part of the survey, the mean age of the respondents were 20.34 years with a SD of 2.07. Majority of the respondents were Hindus coming from an urban background and were pursing their post graduation. 33 respondents reported that they did not use SNS while 137 reported to use social networking sites on a regular basis where $55 \%$ reported to have been spending at least 2 to 4 hours per day on SNS, the most popular being Facebook $(n=132)$ followed by Orkut.

On the Mathews Maladjustment Inventory as seen in the table mentioned below, it was observed that high SNS users $31 \%(n=29)$ had a low level of anxiety whereas the remaining $69 \%(n=66)$ of the respondents reported of high level of anxiety $\left[\chi^{2}=54.992(p<0.05)\right]$. On the paranoia domain for high SNS users similar number of respondents were observed where $31 \%$ experienced low levels of paranoia and $69 \%$ of them experienced higher levels of paranoia value of $\left[\chi^{2}=40.815(p<0.030)\right]$. On the domain of manic tendency it was seen that from the high users of SNS, $29 \%$ of them experienced low levels of manic tendency as against $71 \%$ of them who experienced higher levels of manic tendency $\left[\chi^{2}\right.$ $=49.953(\mathrm{p}<0.05)]$.

Only $32 \%$ of the students experience high inferiority complex problems $\left[\chi^{2}=\right.$ $49.13(\mathrm{p}<0.05)]$ and $29 \%$ of students who are high users of SNS experience higher levels of depression was 
observed $\left[\chi^{2}=80.905, p<0.05\right]$. In case of the general maladjustment for high users of SNS $32 \%$ of the respondents have low maladjustment behaviour while $68 \%$ of them had a higher level of maladjustment behaviour $\left[\chi^{2}=75.031, \mathrm{p}<0.05\right]$.

Table 1 - Cross tabulation of maladjustment and quantity of time spent in SNS

\begin{tabular}{|c|c|c|c|c|c|}
\hline \multirow[t]{2}{*}{ Variables } & \multirow[t]{2}{*}{ Categories } & \multicolumn{4}{|c|}{ Anxiety } \\
\hline & & \multicolumn{2}{|c|}{ Low } & \multicolumn{2}{|c|}{ High } \\
\hline \multirow{4}{*}{$\begin{array}{c}\text { Quantity of time spent in SNS } \\
\qquad \begin{array}{c}\chi^{2}=54.992 \\
\text { df }-2\end{array} \\
\text { Level of significance } 0.020^{*}\end{array}$} & \multirow[b]{2}{*}{ Non users } & $\mathrm{N}$ & $\%$ & $\mathrm{~N}$ & $\%$ \\
\hline & & 20 & 60 & 13 & 40 \\
\hline & Low & 18 & 43 & 24 & 57 \\
\hline & High & 29 & 31 & 66 & 69 \\
\hline Variables & Categories & \multicolumn{4}{|c|}{ Paranoia } \\
\hline \multirow{5}{*}{$\begin{array}{l}\text { Quantity of time spent in SNS } \\
\qquad \begin{array}{c}\chi^{2}=40.815 \\
\text { df }-2 \\
p=0.030^{*}\end{array}\end{array}$} & \multirow{3}{*}{ Non users } & \multicolumn{2}{|c|}{ Low } & \multicolumn{2}{|c|}{ High } \\
\hline & & $\mathrm{N}$ & $\%$ & $\mathrm{~N}$ & $\%$ \\
\hline & & 17 & 52 & 16 & 48 \\
\hline & Low & 14 & 33 & 28 & 67 \\
\hline & High & 31 & 33 & 64 & 67 \\
\hline Variables & Categories & \multicolumn{4}{|c|}{ Manic tendency } \\
\hline \multirow{5}{*}{$\begin{array}{l}\text { Quantity of time spent } \\
\qquad \begin{array}{c}\chi^{2}=49.953 \\
\text { df }-2 \\
p=0.032^{*}\end{array}\end{array}$} & \multirow[b]{3}{*}{ Non users } & \multicolumn{2}{|c|}{ Low } & \multicolumn{2}{|c|}{ High } \\
\hline & & $\mathrm{N}$ & $\%$ & $\mathrm{~N}$ & $\%$ \\
\hline & & 15 & 45 & 18 & 55 \\
\hline & Low & 17 & 40 & 25 & 60 \\
\hline & High & 28 & 29 & 67 & 71 \\
\hline Variables & Categories & \multicolumn{4}{|c|}{ Inferiority } \\
\hline \multirow{5}{*}{$\begin{array}{l}\text { Quantity of time spent } \mathrm{i} \\
\qquad \begin{array}{c}\chi^{2}=49.13 \\
\mathrm{df}-2 \\
\mathrm{p}=0.025^{*}\end{array}\end{array}$} & \multirow{3}{*}{ Non users } & \multicolumn{2}{|c|}{ Low } & \multicolumn{2}{|c|}{ High } \\
\hline & & $\mathrm{N}$ & $\%$ & $\mathrm{~N}$ & $\%$ \\
\hline & & 19 & 57 & 14 & 43 \\
\hline & Low & 22 & 52 & 20 & 48 \\
\hline & High & 65 & 68 & 30 & 32 \\
\hline Variables & Categories & \multicolumn{4}{|c|}{ Depression } \\
\hline \multirow{5}{*}{$\begin{array}{l}\text { Quantity of time spent } \\
\qquad \begin{array}{c}\chi^{2}=80.90 \\
\text { df }-2 \\
p=0.027^{*}\end{array}\end{array}$} & \multirow[b]{3}{*}{ Non users } & \multicolumn{2}{|c|}{ Low } & \multicolumn{2}{|c|}{ High } \\
\hline & & $\mathrm{N}$ & $\%$ & $\mathrm{~N}$ & $\%$ \\
\hline & & 21 & 64 & 12 & 36 \\
\hline & Low & 27 & 64 & 15 & 36 \\
\hline & High & 67 & 71 & 28 & 29 \\
\hline Variables & Categories & \multicolumn{4}{|c|}{ General maladjustment } \\
\hline Quantity of time spent in SNS & & & & & \\
\hline & & $\mathrm{N}$ & $\%$ & $\mathrm{~N}$ & $\%$ \\
\hline$\chi^{2}=75.031$ & Non users & 20 & 61 & 13 & 39 \\
\hline$p=0.039 *$ & Low & 20 & 48 & 22 & 52 \\
\hline & High & 30 & 32 & 65 & 68 \\
\hline
\end{tabular}

(Chi square test used in the assessment. *significant, $\mathrm{p}<0.05=$ significant)

\section{DISCUSSION}

In the current study it was observed that $48 \%$ of the respondents belonged to the age group of 22-24 years. These results are also found to be consistent with other studies as well that have observed SNS users to be in this similar age group ranging from 20 years onwards [1, 11]. It was also seen 
that in the current study that females used SNS and this is corroborative with a study that found that use of SNS is not related to gender and that both male and female have similar number of users [11]. Majority of the students belonged to an urban background. This is probably due to the access of computers and mobiles are seen more in the urban set up as compared to the rural set up. The study also found that Facebook was the most preferred social networking site which is consistent with the findings conducted by next MEDIA" CSA in 2010 which found that Facebook was the number one leading social networking site among users $[1,12]$. However in the Indian context, social networking sites are slowly growing to gain momentum in its popularity and usage but have not yet reached the expectations of the global scenario. This indeed becomes the reason behind $19.4 \%$ non users of SNS.

Respondents who spent more quantity of time on SNS were shown to have a high level of anxiety, manic tendency and paranoia. These findings are consistent with the previous findings that report SNS users to have a high manic tendency $[13,14]$. It is depicted from the results that the quantity of time spent in SNS was inversely proportional to depression and inferiority meaning to say that people who spend more time on SNS have less chances of depression and inferiority. Same patterns have been seen in other studies, that the feeling of being inferior is less among people who use SNS often [13]. It is also seen that the Excessive social networking was found to have many negative effects on an individual's social well being like loneliness, depression, and stress [14, 15]. This is contrary with the present study, may be because of cultural differences.

\section{CONCLUSIONS}

Though this study had found certain interesting findings, firstly the results must be generalized with precaution as it was conducted in a women's college and secondly there may be non sampling errors such as the respondent's opinions and the lack of male respondents restricts the generalization of the study. High social maladjustment was observed in respondents who spend more time in SNS which in turn is affecting their social and personal life. The current estimate of SNS users in India is rapidly increasing and with the advances in technology and mobile internet and with almost every one being able to access these services on their devices, this figure will only serve as a concern for future generations creating a need to address this problem. Research in India on this area can look at the impact of SNS on the academic development as well as focus on promotion of healthy use of social networking sites so as to promote a better and healthier life style among the younger generation.

\section{REFERENCES}

1. Nielsen. Led by Facebook, twitter, global time spent on social media sites up $82 \%$ year over year. 2010. Retrieved from http://www.nielsen.com/us/en/insights/news/2010/led-by-facebook-twitterglobal-time-spent-on-social-media-sites-up-82-year-over-year.html

2. Mooney C. Online Social Networking: Lucent Books; 2009.

3. Boyd DM, Ellison NB. Social Network Sites: Definition, History, and Scholarship. J Comp Med Comm 2007;13(1):210-30.

4. Kreutz C. The next billion - the rise of social network sites in developing countries. 2009 Retrieved from http://www.web2fordev.net/component/content/article/1-latest-news/69-social-networks .

5. Duggan M, Ellison NB, Lampe C, Lenhart A, Madden M. Social Media Update 2014. Pew Research Center USA: 2015.

6. Estatsindia.com. Social media users and usage in 2014. Status quo report. 2013. Retreived from http://www.slideshare.net/Vicks18/social-media-users-usage-in-india-2014-report

7. Renganayar C. Do you have facebook addiction disorder? 2010. Retrieved from Retrieved from http://findarticles.com/p/news-articles/new-straits-times/mi_8016/is_20100801/facebook-addictiondisorder/ai_n54636605/.

8. Mikami AY, Szwedo DE, Allen JP, Evans MA, Hare AL. Adolescent Peer Relationships and Behavior Problems Predict Young Adults' Communication on Social Networking Websites. Dev Psychol 2010;46(1):46-56. 
9. Reid K. The rise of social networking sites. Education Journal. 2009; 119(22). Retrieved March 9, 2014, from

http://search.ebscohost.com/?login.aspx?direct=true\&db=aph\&AN=47781789\&loginpage=Login.asp\&site=e host-live

10. Mathew VG. Manual on Mathews Maladjustment Inventory. Trivandrum, Kerala: Department of Psychology, University of Kerala; 1975.

11. Jafarkarimi H, Sim ATH, Saadatdoost R, Hee JM. Facebook Addiction among Malaysian Students. Int J Inform Educ Technol 2015;6(6):465-9.

12. Stern LA, Taylor K. Social networking on Facebook. J Comm Speech Theatre Assoc N Dakota 2007;20:9-20.

13. Utz S, Beukeboom CJ. The Role of Social Network Sites in Romantic Relationships: Effects on Jealousy and Relationship Happiness. J Comp Med Comm 2011;16(4):511-27.

14. Morahan-Martin J, Schumacher P. Incidence and correlates of pathological Internet use among college students. Comp Hum Behav 2000;16(1):13-29.

15. Akin A, Iskender M. Internet Addiction and Depression, Anxiety and Stress. Int Online J Educ Sci 2011;3(1):138-48.

\author{
Acknowledgements - Nil \\ Source of Funding - Nil \\ Conflict of Interest - Nil
}

